\title{
Especies de poliporáceos poco conocidas en México
}

\author{
Poorly known species of Poliporaceae from Mexico
}

\author{
Ricardo Valenzuela ${ }^{1 *}$, Mauricio R. Palacios-Pacheco ${ }^{1}$, Tania Raymundo ${ }^{1}$ y Silvia Bautista-Hernández ${ }^{2}$ \\ ${ }^{1}$ Laboratorio de Micología, Departamento de Botánica, Escuela Nacional de Ciencias Biológicas, IPN, Apartado postal 260, Centro Operativo Naranjo, \\ Col. Santa María la Rivera, 02600 México, D.F., México. \\ * Becario COFAA y EDD. Correspondencia: rvalenzg@ipn.mx \\ ${ }^{2}$ Colección de Hongos, Departamento de Botánica, Instituto de Biología, UNAM, Apartado postal 70-233, 04510 México,D.F.México
}

\begin{abstract}
Resumen. En el presente trabajo se redescriben 11 especies de hongos poliporoides poco conocidas para México; de las cuales 10 especies ya habían sido citadas para el país, pero no se describieron morfológicamente. Entre ellas tenemos a Fistulina hepatica Shaeffer :Fr., Bjerkandera fumosa (Pers. :Fr.) Karsten, Ceriporia excelsa (Lundell) Parmasto, C. xylostromatoides (Berkeley) Ryvarden et Johansen, Oxyporus populinus (Schum. :Fr.) Donk, Perenniporia tenuis (Schweinitz) Ryvarden, Skeletocutis ochroalba Niemelä, Spongipellis unicolor (Schweinitz) Murrill, Sistotrema confluens Pers. :Fr. y Junghuhnia semisupiniforme (Murrill) Ryvarden. Además, Oligoporus hibernicus (Berkeley et Broome) Gilbertson et Ryvarden, se presenta como nuevo registro para México.
\end{abstract}

Palabras clave: hongos poliporoides, redescripciones, nuevo registro.

\begin{abstract}
We describe 11 species of little known poliporoid fungi from Mexico, of which ten species have been cited from the country, but morphological descriptions have not been presented. The species are Fistulina hepatica Shaeffer: Fr., Bjerkandera fumosa (Pers. :Fr.) Karsten, Ceriporia excelsa (Lundell) Parmasto, Ceriporia xylostromatoides (Berkeley) Ryvarden \& Johansen, Oxyporus populinus (Schum.: Fr.) Donk, Perenniporia tenuis (Schweinitz) Ryvarden, Skeletocutis ochroalba Niemelä, Spongipellis unicolor (Schweinitz) Murrill, Sistotrema confluens Pers.: Fr. and Junghuhnia semisupiniforme (Murrill) Ryvarden. In addition, Oligoporus hibernicus (Berkeley \& Broome) Gilbertson \& Ryvarden represents a new record from Mexico.
\end{abstract}

Key words: Polyporoid fungi, redescriptions, new record.

\section{Introducción}

Los hongos poliporoides se encuentran entre los mejor estudiados (Rossman, 1994) y se conocen alrededor de 2000 especies en el mundo, según estimaciones de RivieroTeixeira (1993). No obstante, se siguen describiendo especies nuevas para la ciencia y la distribución conocida es cada vez más amplia conforme avanzan los estudios regionales en diversas partes del planeta. En México se conocían 357 especies de hongos poliporoides, según los datos presentados por Bandala et al. (1993); desde entonces, se han registrado más de 50 especies que eran desconocidas para la micobiota mexicana, de acuerdo con los trabajos de Pérez-Silva et al. (1993), Valenzuela et al. (1994, 1996, 2002, 2004, 2005), Ryvarden y Guzmán (1993, 2001) y Raymundo y Valenzuela (2003), entre otros. Sin embargo, algunas de las especies registradas presentan problemas taxonómicos y no se cuenta con una descripción detallada del material

Recibido: 07 marzo 2005; aceptado: 01 marzo 2006 mexicano, como en los siguientes casos: Junghuhnia semisupiniformis, que fue descrita por Murrill (1912) como Tyromyces semisupiniformis Murrill de Veracruz y considerada por Lowe (1975) al estudiar el género Tyromyces en Norteamérica; posteriormente Ginns (1980) la cambia al género Flaviporus y Ryvarden (1985), al estudiar las especies descritas por Murrill, al género Junghuhnia. Otro caso es Ceriporia xylostromatoides, que fue registrada por Murrill (1920). Este mismo autor describió a Poria subcorticola como especie nueva de Morelos y Colima; posteriormente fue considerada sinónimo de Poria xylostromatoides por Lowe (1963, 1966), quien estudió los ejemplares mexicanos recolectados por Murrill; después, Ryvarden y Johansen (1980) la transfirieron al género Ceriporia, y Ryvarden (1985) ratificó a Poria subcorticola como sinónimo de dicha especie. Perenniporia tenuis fue citada por Welden y Lemke (1961) de Nuevo León, por Castillo et al. (1969) y Castillo y Guzmán (1970) como Poria tenuis, y por Valenzuela et al. (2002) como Perenniporia tenuis var. tenuis de Querétaro. Oxyporus populinus se menciona en la revisión bibliográfica 
de Bandala et al. (1993) y por Guzmán y Herrera (1971), basándose en el trabajo de Reyes-Garza (1969), quien la citó como Fomes connatus (Weinm.) Gillet de Nuevo León y posteriormente, Valenzuela et al. (2002) la cita de Querétaro. Spongipellis unicolor fue registrada por Laferriére y Gilbertson (1992) de Chihuahua y por Díaz-Moreno et al. (2005) de Durango. Fistulina hepatica, Bjerkandera fumosa y Sistotrema confluens están consideradas en el trabajo de Raymundo y Valenzuela (2003), quienes las citan para el estado de Oaxaca. Finalmente, Ceriporia excelsa y Skeletocutis ochroalba están registradas para la Sierra Madre Oriental por Cifuentes et al. (2004), sin precisar localidad ni entidad federativa. En este trabajo se presenta la redescripción de material mexicano de estas especies. Además, se presenta la descripción de Oligoporus hibernicus que no estaba registrada para México.

\section{Materiales y métodos}

Los ejemplares estudiados se encuentran depositados en las colecciones micológicas de los herbarios ARIZ, BPI, ENCB, FCME, ITAO, LUND, MEXU y NY (Holmgren et al., 1990); así como el de la Universidad Juárez del Estado de Durango (UJED). Se estudiaron 75 ejemplares que pertenecen a 11 especies y 10 géneros clasificados en las familias Fistulinaceae, Polyporaceae, Sistotremataceae y Stecherinaceae. La descripción de los ejemplares se basó en los datos de las etiquetas de campo y en nuevas observaciones de algunos caracteres macroscópicos, los colores se presentan de acuerdo con el manual de Kornerup y Wanscher (1978), y se tomaron tanto del material en fresco como de los ejemplares de herbario. La caracterización microscópica se elaboró con ayuda de laminillas temporales montadas en hidróxido de potasio $(\mathrm{KOH})$ al $5 \%$ y reactivo de Melzer, de acuerdo con los lineamientos que marcan Largent et al. (1977) y Gilbertson y Ryvarden (1986); los colores de las hifas y estructuras himeniales fueron observados en $\mathrm{KOH}$ y se indica si hubo reacción ante el reactivo de Melzer.

\section{Fistulinaceae}

Fistulina hepatica Shaeffer :Fr. Syst. Mycol. 1: 396, 1821. Figs. 1-4.

Basidioma anual, de 80-20 x 40-75 x 20-50 mm, pileadoestipitado, flabeliforme, de consistencia carnosa en fresco a correosa en ejemplares de herbario, solitario. Píleo dimidiado a reniforme, con la superficie radialmente estriada, ligeramente pegajosa en fresco, viloso a híspido en ejemplares jóvenes, glabrescente con la edad, de color café amarillento a café rojizo en fresco, café oscuro (7F7) a negro en ejemplares herborizados; margen entero, obtuso, ligeramente involuto, fértil, concoloro con la superficie del píleo. Himenóforo con poros circulares, de 5 a 6 por $\mathrm{mm}$, de color café claro (6E7), café oscuro (6F8) hacia el margen, con el borde entero. Tubos individuales, separables unos de otros, de 3-5 mm de longitud, concoloros con los poros. Estípite de 30-60 x 15-30 mm, lateral, ventricoso, pubescente a ligeramente viloso, granuloso en algunas porciones y liso en otras, concoloro con el píleo. Contexto de 20-40 mm de grosor, simple, carnoso y acuoso, de color rojizo en fresco y café obscuro a negro en especimenes de herbario.

Sistema hifal monomítico con hifas generativas de 3.2-5.0 $\mu \mathrm{m}$ de diámetro, con fíbulas, hialinas, de paredes delgadas. Hifas gleopleróticas hasta $5.6 \mu \mathrm{m}$ de diámetro, de color amarillo dorado, presentes en la superficie del estípite. Elementos cistidioides presentes en el borde de los tubos, de 65-115 x 6-12 $\mu \mathrm{m}$, hialinos a amarillo dorado en $\mathrm{KOH}$, con pared delgada y algunos son septados. Basidios de 18-28 x 5$7 \mu \mathrm{m}$, tetraspóricos, hialinos, claviformes. Basidiosporas de 4.0-5.2 x 3.2-4.0 $\mu \mathrm{m}$, ovoides a lagrimoides, hialinas a pálido amarillentas en $\mathrm{KOH}$, lisas, de pared delgada, inamiloides.

Material estudiado. ESTADO DE MÉXICO: municipio de Valle de Bravo, alrededores de Valle de Bravo, agosto 8, 1971, Salas s.n (ENCB). OAXACA: municipio de Ixtlán de Juárez, distrito Ixtlán, La Cumbre, julio 4, 1966, A. J. Sharp 3916 (MEXU). VERACRUZ: municipio de Atzalán, La Calavera, abril 28, 1978, F. Ventura 15241 (ENCB). SUECIA: Skane, Dalby, septiembre 16, 1950, Olof Andersson s.n. (LUND, ENCB).

Comentarios taxonómicos. Esta especie crece solitaria sobre madera muerta de Quercus causando pudrición café en bosque de Pinus-Quercus o Quercus. Fistulina hepatica es muy parecida a F. guzmanii Brusis, pero esta última presenta colores más brillantes (rojo carmín o rojo púrpura) en fresco, tanto en el píleo como en el himenóforo, el tamaño del basidioma es generalmente más pequeño y sólo se ha encontrado sobre Mimosa galeottii Benth, como lo señala Brusis (1972). Fistulina hepatica sólo crece sobre Quercus y Castanea en Norteamérica y Europa (Gilbertson y Ryvarden, 1986; Farr et al., 1989). En cuanto a los caracteres microscópicos, el tamaño de las esporas es muy similar en ambas especies, y Brusis (1972) no menciona la presencia de los elementos cistidioides en el borde de los tubos en $F$. guzmanii. Las diferencias morfológicas entre ambas especies son suficientes para considerarse como especies distintas y sería necesario corroborarlo con un análisis molecular. Es una especie común en Norteamérica (Gilbertson y Ryvarden, 1986). En México, sólo se ha registrado en el estado de Oaxaca por Raymundo y Valenzuela (2003).

\section{Polyporaceae}

Bjerkandera fumosa (Pers.: Fr.) Karsten. Medd. Soc. Fauna Fl. Fenn. 5:38, 1879. Figs. 5-7.

Basidioma anual, pileado-sésil, imbricado, dimidiado a ampliamente adherido, correoso a duro cuando seco, de 1928 x 10-15 x 4-6(7) mm, crece sobre madera muerta causando pudrición blanca. Píleo semicircular, anchamente adherido, azonado y aterciopelado, de color naranja pálido (5A2) a 

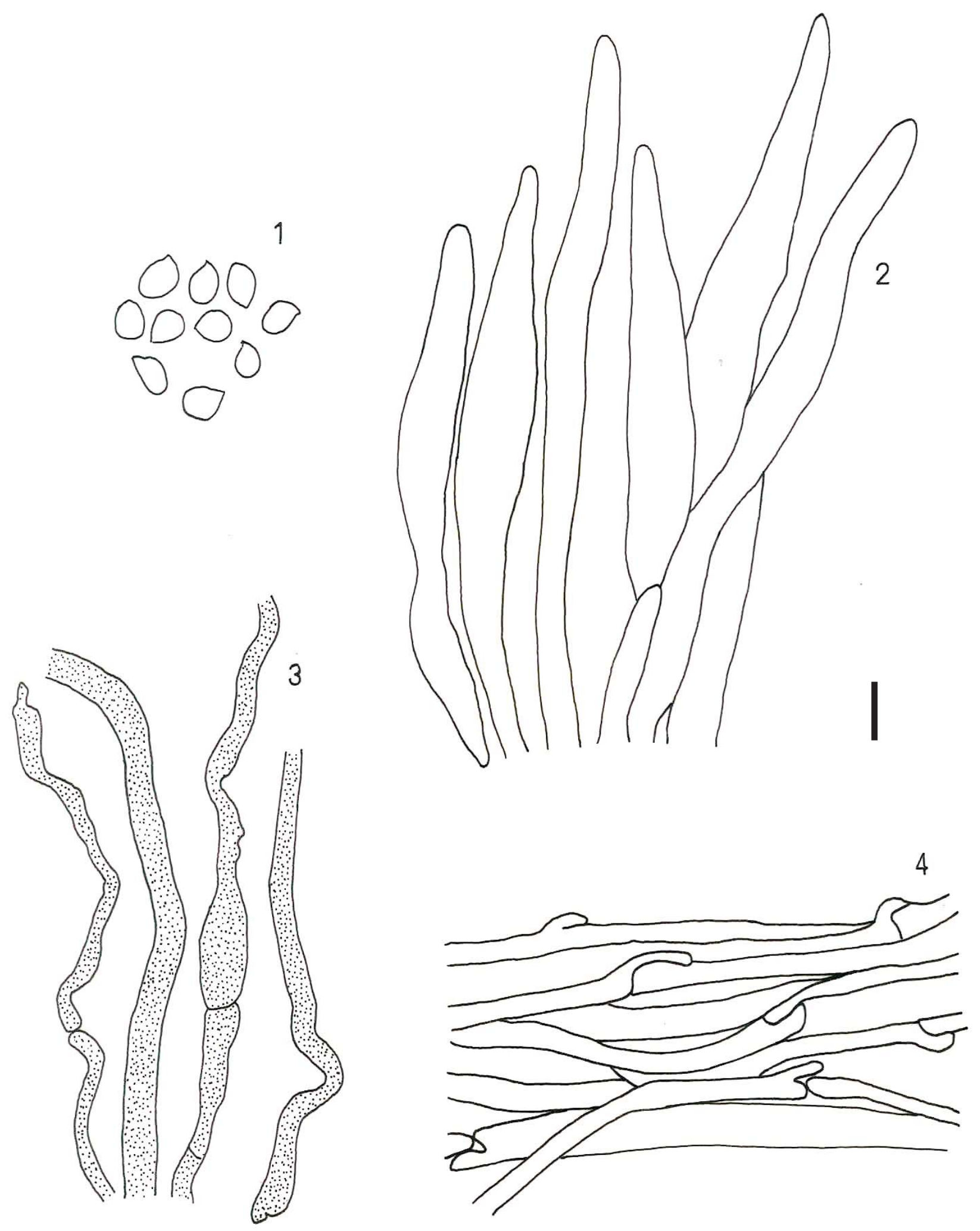

Figuras 1-4. Fistulina hepatica Shaeffer: Fries; 1, basidiosporas; 2, hifas del pileipelis; 3, hifas gleopleróticas; 4, sistema hifal (escala $=8 \mu \mathrm{m})$. 

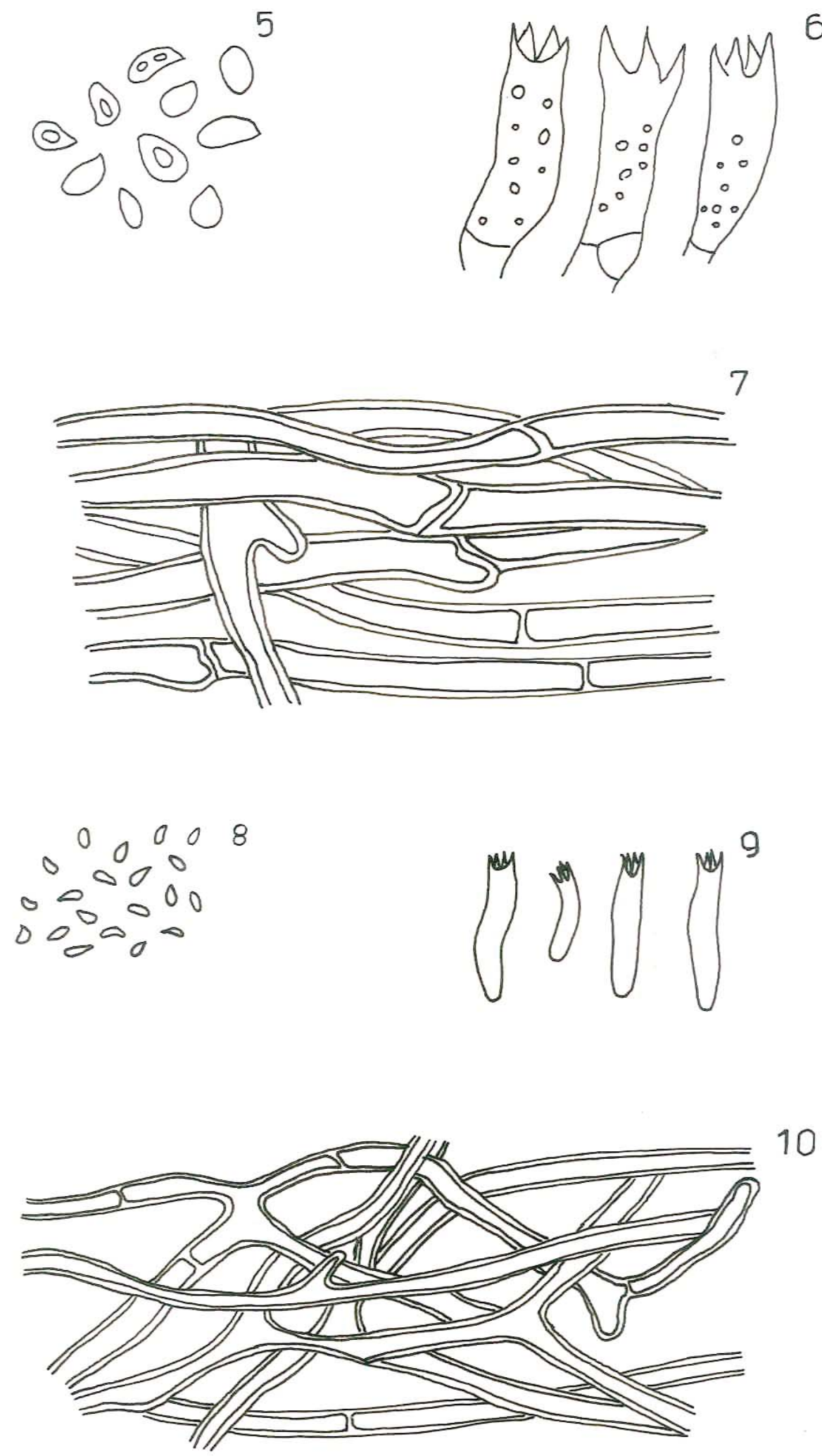

Figuras 5-10. Bjerkandera fumosa (Persoon: Fr.) Karsten (5-7); 5, basidiosporas; 6, basidios; 7, sistema hifal. Ceriporia excelsa (Lundell) Parmasto (8-10); 8, basidiosporas; 9, basidios; 10, sistema hifal (escala $=8 \mu \mathrm{m})$. 
gris naranja pálido (5A-B3), con tonos café grisáceo (5CD2) a gris (5F2) hacia el borde. Margen recurvado, entero, ondulado cuando seco. Himenóforo con poros angulares de 3-5 por mm, color café grisáceo en diferentes tonos (5D-E y F2). Tubos concoloros al himenóforo hasta de $1 \mathrm{~mm}$ de longitud. Contexto, concoloro con el píleo, de 1 a $3 \mathrm{~mm}$ de grosor, con una línea de color café oscuro en la base de los tubos.

Sistema hifal monomítico, hifas del contexto de 3.2-4.0 $\mu \mathrm{m}$ de diámetro, hialinas, inamiloides, de pared delgada, con fíbulas y ramificaciones frecuentes, formando una trama entrelazada, hifas de la línea obscura de color café. Hifas de la trama himenoforal de 2.4-4.0 $\mu \mathrm{m}$ de diámetro, hialinas, inamiloides, de paredes delgadas, fíbulas abundantes y frecuentemente ramificadas, presentan una disposición subparalela a entrelazada. Basidios de 13-16 x 4.8-5.6 $\mu \mathrm{m}$, clavados, hialinos e inamiloides. Basidiosporas de 4.8-5.6 (-6.4) x 2.4-3.2 $\mu \mathrm{m}$, de pared delgada, oblongas a oblongoelipsoides, lisas, hialinas e inamiloides.

Material estudiado. ESTADO DE MÉXICO: municipio de Acambay, Km 1-2.5 del entronque de la carretera Panamericana-Agostadero, agosto 22, 1983, A. EstradaTorres 891B (ENCB); municipio de Acolman, Santa Catarina, col. Emiliano Zapata, febrero 3, 1980, J. Gómez 103 (ENCB); municipio de Ixtapaluca de Rayón, Km 56 autopista México-Puebla, Llano Grande, $3 \mathrm{~km}$ al $\mathrm{SO}$ de Río Frío, agosto 10, 1969, García-Romero 11 (ENCB); municipio de Ocoyoacac, Parque Nacional Miguel Hidalgo y Costilla, $10 \mathrm{~km}$ al NE de Ocoyoacac, octubre 9, 1983, L. Colón 463 B (ENCB); municipio de Toluca, $4.5 \mathrm{~km}$ adelante de la estación meteorológica del Nevado de Toluca, octubre 25, 1970, G. Guzmán 8526 (ENCB). HIDALGO: municipio de Acaxochitlán, $2 \mathrm{~km}$ al SO de la Presa del Tejocotal, julio 26, 1980, G. Guzmán s.n. (ENCB). OAXACA: municipio de San José Lachiguri, distrito Tehuantepec, $10 \mathrm{~km}$ al S de Guegovela, diciembre 19, 1977, J. Pérez-Ortiz 1134 (ENCB). VERACRUZ: municipio de Acajete, El Rodeo, diciembre 10, 1979, F. Ventura 16681 (ENCB).

Comentarios taxonómicos. Esta especie se encuentra creciendo sobre madera muerta de Abies, Pinus y Quercus en bosques de coníferas y Pinus-Quercus y causa pudrición blanca en duramen. Bjerkandera fumosa es muy afín a $B$. adusta, pero están separadas porque la primera presenta en el contexto una línea obscura que separa los tubos y los poros más grandes como lo señalan Gilbertson y Ryvarden (1986). Esta especie se distribuye en Norteamérica, en los bosques deciduos del este y las regiones de la costa pacífica (Gilbertson y Ryvarden, 1986). En México se registró por primera vez en Tehuantepec, estado de Oaxaca (Raymundo y Valenzuela, 2003).

Ceriporia excelsa (Lundell) Parmasto. Spor. Rast, 12: 222, 1959. Figs. 8-10
Basidioma anual de 10-23 x 8-10 mm, resupinado, de consistencia corchosa. Margen estéril, obtuso, de color crema (4A3), pubescente, hasta $1 \mathrm{~mm}$ de grosor. Himenóforo con poros angulares a ligeramente alargados, 1-3 por mm, blanquecinos a color café (4A3 y 5D8) en ejemplares herborizados. Tubos hasta $2 \mathrm{~mm}$ de profundidad, concoloros al himenóforo, con el borde delgado y lacerado en algunas partes. Subículo de menos de $1 \mathrm{~mm}$ de grosor, de color blanquecino y azonado.

Sistema hifal monomítico, hifas generativas, ramificadas, con septos simples, de 4.0-6.4 $\mu \mathrm{m}$ de diámetro, de paredes delgadas a gruesas, hialinas e inamiloides. Células estériles ausentes. Basidios de 12-24 x 3.2-5.0 $\mu \mathrm{m}$, clavados, tetraspóricos, con esterigmas de hasta $2.4 \mu \mathrm{m}$ de largo, hialinos, inamiloides, poco abundantes. Basidiosporas de 3.2-5.6 x 1.6-2.4 $\mu \mathrm{m}$, oblongas a cilíndricas, lisas, hialinas, inamiloides, poco abundantes.

Material estudiado. HIDALGO: municipio de Tlanchinol, Lontla, mayo 12, 1985, S. Ojeda 112 (ENCB).

Comentarios taxonómicos. Esta especie se encontró creciendo sobre madera muerta de angiospermas en un bosque mesófilo de montaña y ocasiona una pudrición blanca. Es parecida a C. tarda (Berkeley) Ginns y C. viridans (Berkeley et Broome) Donk, pero se separan fácilmente por la coloración rosada de la primera y verdosa en la segunda; además, ambas presentan poros más pequeños de 3-5 por milímetro. Ceriporia xylostromatoides, especie que también se encuentra en México, se separa por tener esporas globosas y poros más pequeños de 3-5 por milímetro (Gilbertson y Ryvarden, 1986). Ceriporia excelsa es una especie de amplia distribución en Norteamérica (Gilbertson y Ryvarden, 1986), en Europa sólo se conoce en Oslo y en Ormtjernkampen Nat. Park, en Noruega; en Suecia se recolectó en la región de Goteborg (Ryvarden, 1976).

Ceriporia xylostromatoides (Berkeley) Ryvarden \& Johansen. Prelim. Polyp. Fl. East. Afr. p 276, 1980. Figs. 11-13.

Basidioma anual, de 38 × 23 × $0.5 \mathrm{~mm}$, resupinado, de consistencia papirácea. Margen fértil, de color amarillo pálido (4A3). Himenóforo con 3-4 poros por mm, angulares, de color amarillo pálido (4A3) a naranja pálido (5A3), con el borde dentado. Tubos hasta de $1 \mathrm{~mm}$ de grosor, concoloros con el himenóforo. Contexto simple, hasta de $1 \mathrm{~mm}$ de grosor, de color amarillo pálido (4A3).

Sistema hifal monomítico, hifas generativas de 3.2-5.6 $\mu \mathrm{m}$ de diámetro, con septos simples, hialinas, inamiloides, de paredes delgadas, de simples a ramificadas. Basidios de 8.814.4 x 5.6-7.2 $\mu \mathrm{m}$, tetraspóricos, con esterigmas de $2.4 \mu \mathrm{m}$ de largo, hialinos, inamiloides. Basidiosporas de 4.8-5.6 x 4.0-4.8 $\mu \mathrm{m}$, ovoides, lisas, hialinas, inamiloides.

Material estudiado. MORELOS: municipio de Cuernavaca, 

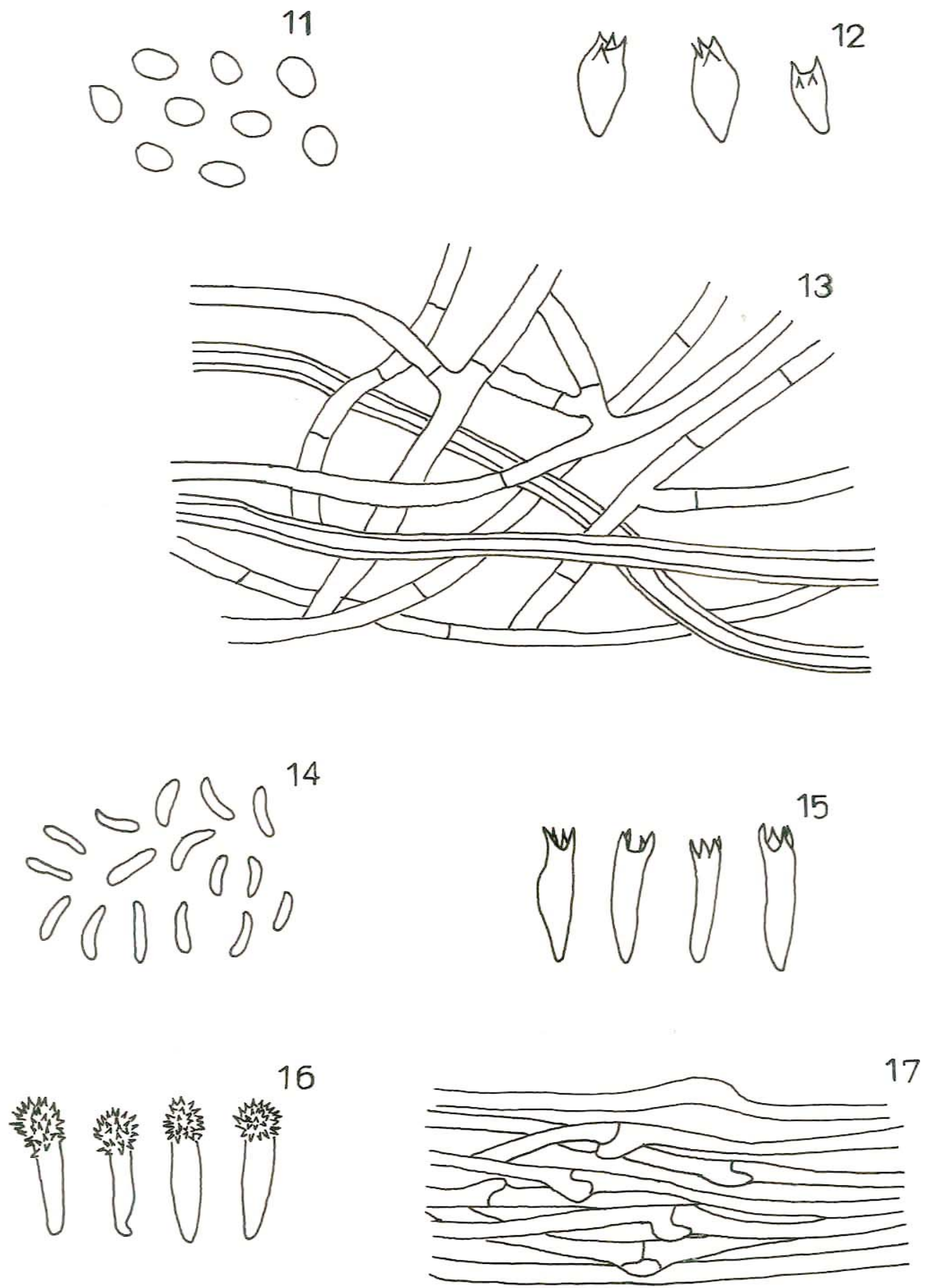

Figuras 11-17. Ceriporia xylostromatoides (Berkeley) Ryvarden et Johansen (11-13); 11, basidiosporas; 12, basidios; 13, sistema hifal. Oligoporus hibernicus (Berkeley et Broome) Gilbertson et Ryvarden (14-17); 14, basidiosporas; 15, basidios; 16, cistidios hifoides; 17, sistema hifal (escala $=8 \mu \mathrm{m})$. 
jardines y barrancas cercanos a Cuernavaca, diciembre 24-27, 1909, W.A. Murrill y E.L. Murrill BPI-US243410 (ISOTIPO de Poria subcorticola Murrill, NY). QUERÉTARO: municipio de Pinal de Amoles, Km 162 de la carretera San Juan del Río-Jalpan, La Cuesta, mayo 18, 1987, $R$. Fernández 3909 (ENCB). SINALOA: municipio de San Miguel, 15 millas al S de Culiacán, diciembre 29, 1994, $R$. L. Gilbertson 20081 (ARIZ). SONORA: Arroyo el Huerotal, septiembre 12, 1994, R. L Gilbertson 19761, 19795, 19840, T. R. Van Devender 19840 (ARIZ); Arroyo la Bajada, al E del río Cuchujaqui, $3 \mathrm{Km}$ al O de Los Muertos, diciembre 4, 1994, T. R. Van Devender 94914 (ARIZ); Arroyo Guerocoba, cerca de El Sabino, marzo 16, 1994, T. R. Van Devender 94191 A (ARIZ); cerro Huicharobi, 4 Km al SO de Basuroa, diciembre 5, 1994, T. R. Van Devender 94931 (ARIZ); 1 Km sobre el arroyo El Metidero, río Cuchujaqui, $12.4 \mathrm{Km}$ al S de Álamos, octubre 31, 1994, T. R. Van Devender 94848 (ARIZ); $3.2 \mathrm{Km}$ al N de El Sabino, Arroyo el Tulillo, s/f, T. R. Van Devender $s / n$ (ARIZ); Rancho La Sierrita, E de la Sierra de Álamos, $5.5 \mathrm{Km}$ al W de Álamos, s/f, T. R. Van Devender $s / n$ (ARIZ).

Comentarios taxonómicos. Esta especie se encontró creciendo en madera y hojas muertas de angiospermas y sobre otros hongos (Ganoderma y Coriolopsis) en bosque de Pinus-Quercus y bosque tropical caducifolio y ocasiona una pudrición blanca. Ceriporia xylostromatoides se caracteriza por presentar esporas globosas, lo que la diferencia de las demás especies descritas en este género que generalmente presentan esporas oblongas a cilíndricas y algunas son alantoides. Esta especie se distribuye en zonas tropicales y subtropicales de Australia y el este de África (Ryvarden y Johansen, 1980) y en el sureste de Norteamérica (Gilbertson y Ryvarden, 1986).

Oligoporus hibernicus (Berkeley et Broome) Gilbertson et Ryvarden. Mycotaxon 22:364, 1985. Figs. 14-17.

Basidioma anual, resupinado a efuso-reflejo, de 1-2 mm de grosor y forma irregular. Píleo reducido, color blanco a blanco amarillento (4-5A 2), velutinoso, estrigoso cuando seco. Himenóforo con poros angulares, de 3-5 por mm, más pequeños hacia el borde, blanquecinos a grisáceos (4B2,5B2), en seco amarillento a anaranjado pálido (5A2-3), con tonos anaranjados (5A4) y blanquecino hacia el borde (4A1-2). Tubos de 1-2 mm de longitud, finamente pubescentes en el borde. Contexto simple, de color blanco y menor de $0.5 \mathrm{~mm}$ de grosor.

Sistema hifal monomítico con hifas generativas de pared delgada, de 3.2-4.0 $\mu \mathrm{m}$ de diámetro, con abundantes fíbulas y frecuentes ramificaciones, hialinas e inamiloides; hifas de la trama himenoforal, con disposición entrelazada, con un arreglo más o menos helicoidal. Cistidios hifoides presentes en el himenio, cilíndricos, adelgazados hacia la base, hialinos, con incrustaciones apicales que se disuelven en $\mathrm{KOH}$, visibles en Melzer, difíciles de observar en la porción media y basal de los tubos, más frecuentes en el disepimento. Basidios cilíndricos a ligeramente clavados, tetraspóricos, de pared delgada, hialinos e inamiloides. Basidiosporas de 4.86.4(-7.2) x $0.8 \mu \mathrm{m}$, cilíndricas, de pared delgada, hialinas a amarillentas y amiloides.

Material estudiado. ESTADO DE MÉXICO: municipio de Amecameca de Juárez, 2-5 km al E de San Pedro Nexapa, cañada de Nexpayantla, julio 27, 1975, G. Guzmán 12278 (ENCB).

Comentarios taxonómicos. Esta especie se encontró creciendo en madera muerta de Abies, en bosque de coníferas y ocasiona una pudrición café. Oligoporus hibernicus se caracteriza por los cistidios con incrustaciones en el ápice y esporas alantoides, caracteres que la hacen diferente de las otras especies del género Oligoporus (Gilbertson y Ryvarden, 1987). Dicha especie tiene amplia distribución en Norteamérica (Gilbertson y Lowe, 1962). En este trabajo se describe por primera vez para México.

Oxyporus populinus (Schum.: Fr.) Donk. Med. Bot, Mus. Univ. Utrech 9: 204, 1933. Figs. 18-21.

Basidioma anual, de 50 × 35 x $15 \mathrm{~mm}$, pileado-sésil, de consistencia corchosa. Píleo de color naranja pálido (5A3) a naranja brillante (5A4), liso, sulcado concéntricamente. Margen estéril, incurvado, de color anaranjado pálido (5A3). Himenóforo con poros angulares, de 5-7 por milímetro, de color anaranjado grisáceo (5B6) a anaranjado pardo (5C6), con borde liso. Tubos concoloros al margen, hasta 5 $\mathrm{mm}$ de longitud. Contexto hasta $10 \mathrm{~mm}$ de grosor, simple, ligeramente zonado o azonado en algunos especimenes, corchoso, de amarillo pálido (4A3) a amarillo brillante (4A4).

Sistema hifal monomítico, con hifas generativas de 2.5$4.5 \mu \mathrm{m}$ de diámetro, septos simples, hialinas, inamiloides, de simples a poco ramificadas, de paredes gruesas. Basidios de 12-13.6 x 4-4.8 $\mu \mathrm{m}$, ovoides a clavados, tetraspóricos. Cistidios de 19-32 x 4-4.8 $\mu \mathrm{m}$, abundantes, de cilíndricos a capitados y con cristales incrustados en el ápice los que se disuelven en $\mathrm{KOH}$, con paredes delgadas. Basidiosporas de 3.5-4.5 x 2.4-4 $\mu \mathrm{m}$, subglobosas, lisas, hialinas, inamiloides.

Material estudiado. QUERÉTARO: Landa de Matamoros, Km 230 carretera Jalpan-Xilitla, octubre 6, 1984, J. Cruz 314 (ENCB). EUA: MICHIGAN: Herbar Springs, septiembre 14, 1932, E.B. Mains 32-756 (MICH, ENCB), OHIO: Delaware Co., Camp. Lazasus Boy Scout, Reserve, agosto 7, 1968, W.B. Cooke (Herb. Cooke, ENCB).

Comentarios taxonómicos. Oxyporus populinus crece sobre Quercus en bosque de Quercus-Pinus, ocasionando pudrición blanca. Esta especie se caracteriza por presentar basidiomas de color crema a anaranjado y por el tamaño y forma de las esporas, aunque los especímenes mexicanos son jóvenes y sólo presentan una capa de tubos, el resto de los caracteres concuerda con la descripción de Gilbertson y Ryvarden 
<smiles>O=S(=O)(O)O</smiles>
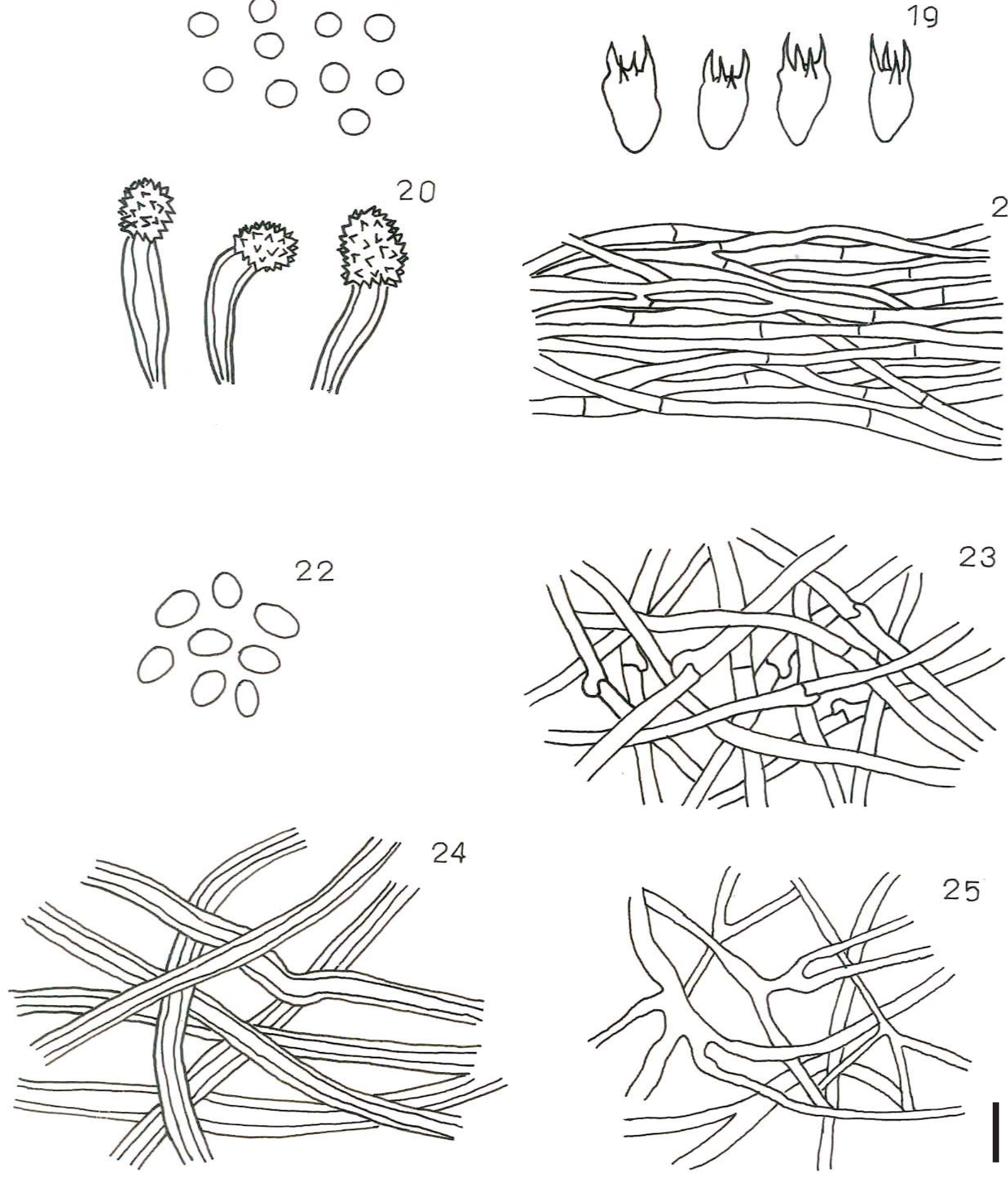

Figuras 18-25. Oxyporus populinus (Schumacker: Fr.) Donk (18-21); 18, basidiosporas; 19, basidios; 20, cistidios; 21, sistema hifal. Pereniporia tenuis (Schweinitz) Ryvarden var tenius (22-25); 22, basidiosporas. Sistema hifal: 23, hifas generativas; 24, hifas esqueléticas; 25 , hifas conectivas (escala $=8 \mu \mathrm{m})$. 
(1987). Una especie parecida es Oxyporus nobilissimus, que presenta basidiomas muy grandes, himenóforo con poros más grandes y cistidios con paredes engrosadas; además, sólo se ha encontrado creciendo sobre coníferas (Gilbertson y Ryvarden, 1987). Esta especie se conoce de Australia y en África se mencionó de Kenia (Ryvarden y Johansen, 1980); además es común en Europa central y el norte de Asia. Para Norteamérica se ha registrado de los bosques decíduos del centro de EUA y Nuevo México, y para Canada, de Columbia Británica.

Perenniporia tenuis (Schweinitz) Ryvarden, Norw. J. Bot. 20:9, 1973. Figs. 22-25.

Basidioma anual, de 87-99 x 22-26 × 3 mm, resupinado, de consistencia corchosa, de color crema a amarillo pálido. Margen estéril, redondeado, de color amarillo blanquecino (4A2). Himenóforo con poros circulares a angulares, de 3-5 por $\mathrm{mm}$, de color blanco amarillento a crema (4A2; 4A3) con tonos más oscuros de color café claro (5D4) al secarse, con el borde liso. Tubos concoloros con el himenóforo, hasta de $2 \mathrm{~mm}$ de longitud. Contexto simple, esponjoso, de color gris amarillento (5C4), hasta de $1 \mathrm{~mm}$ de grosor.

Sistema hifal trimítico con hifas generativas de 2.0-4.0 $\mu \mathrm{m}$ de diámetro, fibuladas, hialinas, inamiloides, de simples a poco ramificadas, de paredes delgadas. Hifas esqueléticas de 3.0-6.0 $\mu \mathrm{m}$ de diámetro, hialinas, inamiloides. Hifas conectivas de 2.0-5.0 $\mu \mathrm{m}$ de diámetro, hialinas, inamiloides, frecuentemente ramificadas, de paredes delgadas. Cistidios ausentes. Basidios no observados. Basidiosporas de 5.66.4 x 4.0-5.6 $\mu \mathrm{m}$, ampliamente elipsoides, lisas, de paredes delgadas, hialinas e inamiloides.

Material estudiado. ESTADO DE MÉXICO: municipio de Tejupilco de Hidalgo, Km 8 de la terracería a cañadas de Nanchititla, julio 31, 1988, R. Valenzuela 6680, 6682 (ENCB). QUERÉTARO: municipio de Landa de Matamoros, Km 230 de la carretera Jalpan-Xilitla, Parador Santa Martha, septiembre 17, 1992, R. Valenzuela 7345 (ENCB). SONORA: Arroyo El Huerotal, diciembre 30, 1994, R. L. Gilbertson 20214 (ARIZ).

Comentarios taxonómicos. Esta especie crece en abundancia en bosque de pino-encino y en bosque tropical caducifolio con Alnus sobre madera de Alnus y Quercus. Se reconoce por sus basidiomas resupinados de color crema a amarillo pálido y por sus esporas inamiloides que la hacen diferente de $P$. medula-panis que presenta esporas de paredes gruesas truncadas y dextrinoides. Ampliamente distribuida en las regiones boscosas de Norteamérica (Gilbertson y Ryvarden, 1987), en tanto que para Europa sólo la menciona de Noruega, Reino Unido y Finlandia. En México se ha citado de Nuevo León (Castillo et al., 1969; Castillo y Guzmán, 1970; Welden y Lemke, 1961), Valle de México (Zarco, 1986) sin precisar localidad ni materiales estudiados, y de Querétaro (Valenzuela et al., 2002); por su parte, Bandala et al. (1993) la enlistan de Guerrero; pero al revisar las fuentes originales no se encontró citada esta especie para tal entidad.

Skeletocutis ochroalba Niemelä. Nat. Can. 112:466, 1985. Figs. 26-29.

Basidioma anual, pileado-sésil a efuso-reflejado o resupinado. Píleo flabeliforme a semicircular, anchamente adherido, blanco a amarillento naranja (5A2-3), radialmente estriado al secar, borde entero y margen conchado a recurvado. Himenóforo con poros angulares, de 7-9 por milímetro, de color blanco a amarillento (4A3) al secar, pero los poros se conservan blancos cerca del borde; con la edad el borde se alarga a manera de dientes. Contexto simple, blanquecino a amarillento (4A2) al secar, de menos de $5 \mathrm{~mm}$ de grosor.

Sistema hifal trimítico, hifas generativas de 2.4-3.2 $\mu \mathrm{m}$ de diámetro, hialinas e inamiloides, de paredes gruesas (más o menos $0.5 \mathrm{~mm}$ de grosor), con fíbulas y algunas ramificaciones, dispuestas de manera entrelazada en el contexto, donde son poco frecuentes; en el subhimenio, de pared delgada, con una disposición más o menos paralela; así mismo ocurre en la trama, donde son más abundantes que en el contexto, con incrustaciones, muy evidentes en la zona basal de los tubos y en el contexto, donde éstas son escasas. Hifas esqueléticas enteras, con pared gruesa (hasta $1 \mu \mathrm{m}$ de grosor), tortuosas y entrelazadas en el contexto. Basidios de 12-15.2 $\times$ 3.2-4.8 $\mu \mathrm{m}$, clavados, de pared delgada, hialinos, inamiloides. Basidiosporas de 3.2-4.8 x 0.7-0.8 $\mu \mathrm{m}$, cilíndricas, lisas, de pared delgada, hialinas e inamiloides.

Material estudiado. ESTADO DE MÉXICO: municipio de Ixtapaluca de Rayón, Km 56 de la autopista México-Puebla, cerca de Río Frío, Llano Grande, septiembre 8, 1995, M. R. Palacios 387 (ENCB). HIDALGO: municipio de Tlanchinol, Km 157 carretera Pachuca-Tampico, julio 25, 1987, $R$. Valenzuela 6225 (ENCB).

Comentarios taxonómicos. Esta especie crece en bosque de coníferas, causando pudrición blanca en Pinus. Una especie afín es $S$. nivea, pero se separa porque presenta poros más pequeños que $S$. ochroalba y sólo se ha encontrado creciendo sobre angiospermas. El único registro de esta especie era de la bahía de Hudson en la provincia de Quebec. Canadá.

Spongipellis unicolor (Schweinitz) Murrill. North. Am. Flora 9: 37, 1907. Figs. 30-33.

Basidioma de 90 x 50 x 20 mm, sésil, pileado, de dimidiado a ungulado, adherido, esponjoso. Píleo con colores amarillo pálido y naranja (4A3, 4A4 y 5A4), aplanado, tomentoso, surcado con dos depresiones en forma semicircular, simple, solitario. Margen fértil, agudo de color amarillo (6D5). Himenóforo con poros con colores ladrillo y amarillo pálido cuando seco (5A3 y 6D5), de circulares a angulares, de 1-2 $\mathrm{mm}$ de ancho, con el borde dentado. Tubos hasta de $5 \mathrm{~mm}$ de profundidad de color amarillo pálido (5A2). Contexto hasta con $15 \mathrm{~mm}$ de grosor, concoloro y zonado con la parte de arriba esponjosa y la parte de abajo pegada al himenio fibroso. 


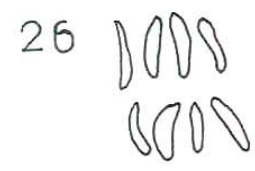

27<smiles>[AlH2]</smiles>

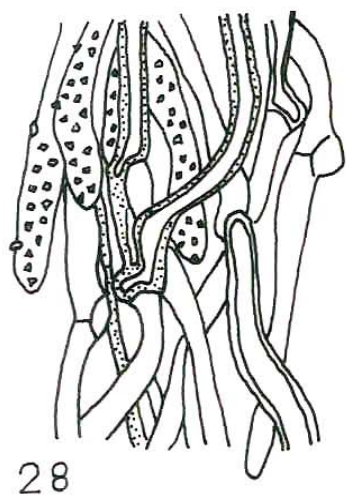

28

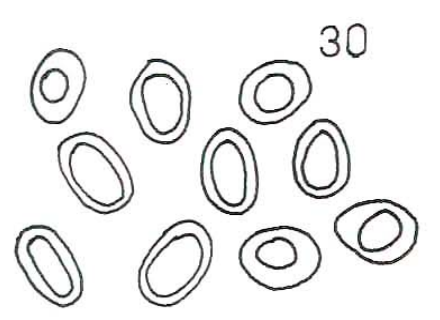

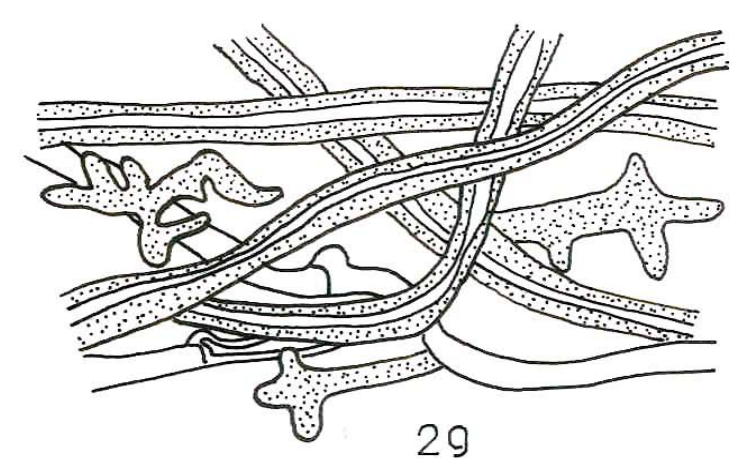

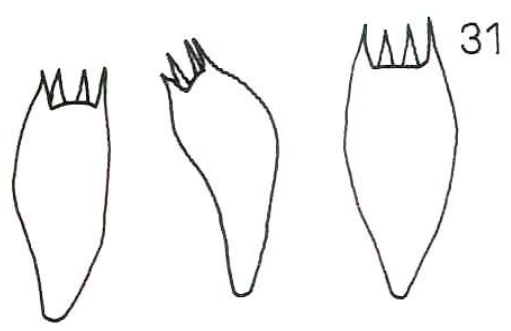

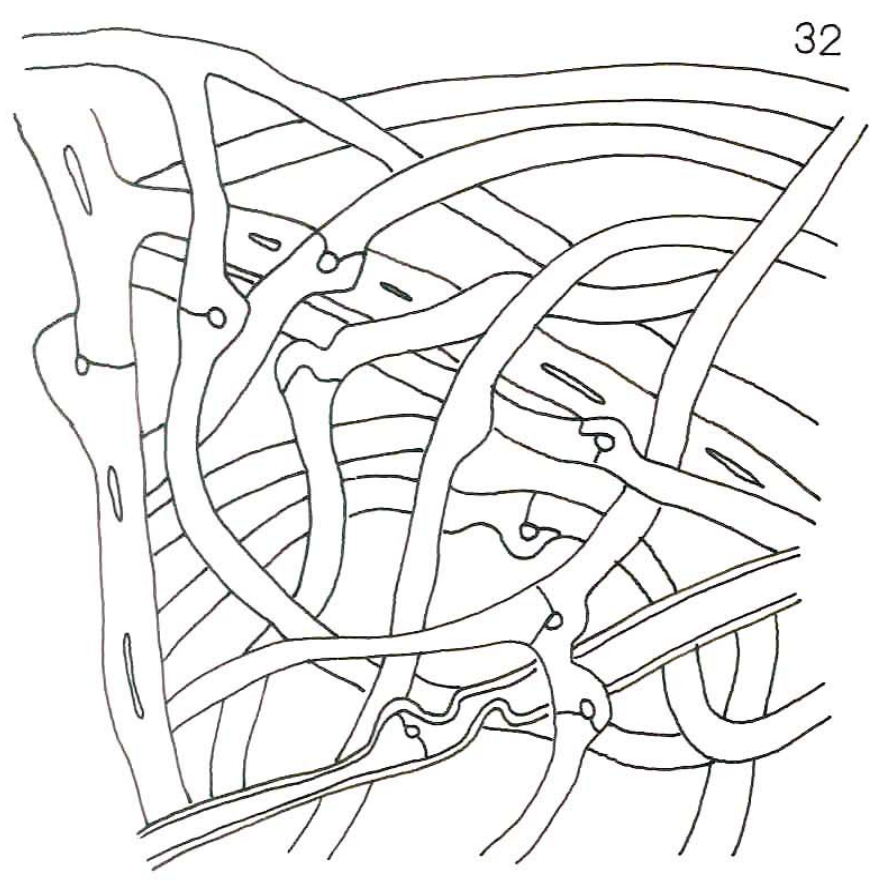

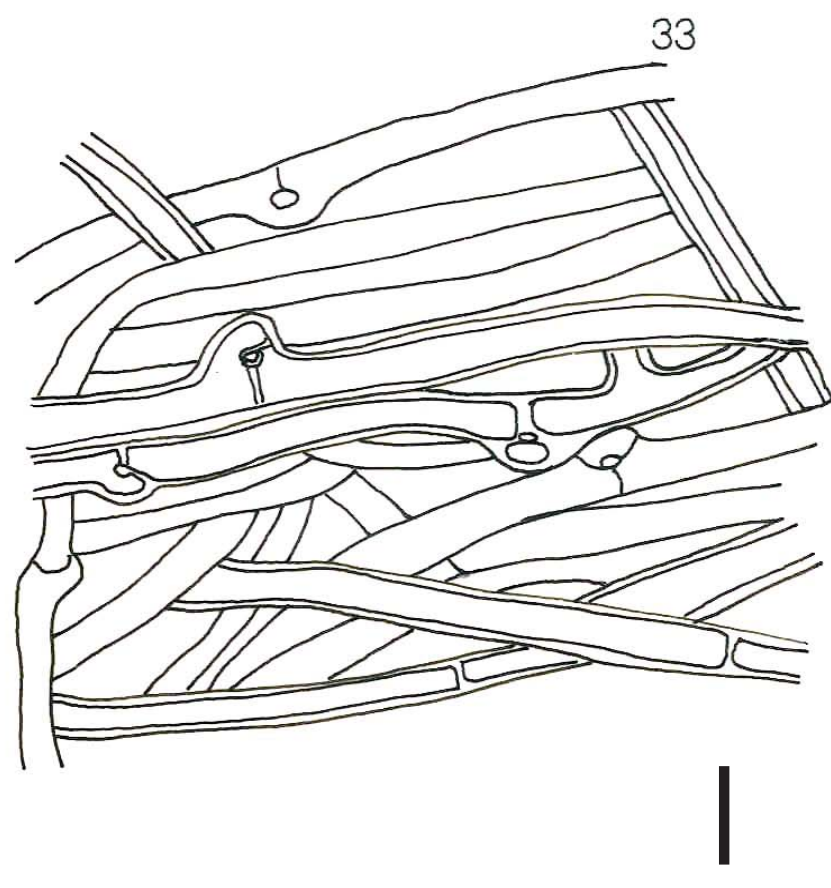

Figuras 26-33. Skeletocutis ochroalba Niemalä (26-29); 26, basidiosporas; 27, basidios. Sistema hifal: 28, trama himenoforal; 29, hifas del contexto. Spongipellis unicolor (Schweinitz) Murrill (30-33); 30, basidiosporas; 31, basidios. Sistema hifal: 32, trama himenoforal; 33, hifas contextuales (escala $=8 \mu \mathrm{m})$. 
Sistema hifal monomítico, con hifas generativas, fibuladas, hialinas, inamiloides, frecuentemente ramificadas, las de la trama de 2-4 $\mu \mathrm{m}$ de diámetro y las paredes poco gruesas, las del contexto con mayor diámetro, de 3.2-4.8 $\mu \mathrm{m}$ y paredes más gruesas $(0.8 \mu \mathrm{m})$. No se observaron cistidios ni otros elementos estériles. Basidios de 26-30 x $10 \mu \mathrm{m}$, clavados, tetraspóricos, esterigmas hasta de $3.2 \mu \mathrm{m}$ de largo, hialinos, inamiloides, poco abundantes. Basidiosporas de 6.4-8.0 x 4.8-7.2 $\mu \mathrm{m}$, ovoides a elipsoides, lisas, hialinas, abundantes.

Material estudiado. CHIHUAHUA: municipio de Temósachi, Nabogame, agosto de 1988, J. E. Laferriere1901, 1968 (ARIZ). DURANGO: municipio de Guanacevi, NO de Guanacevi, entre Los Ángeles y Coconoi, noviembre 5, 1991, R. Díaz 133 (ESB-UJED). HIDALGO: municipio de Huasca de Ocampo, camino a San Miguel Regla, julio 28, 1968, G. Guzmán 6870-B (ENCB); julio 19, 1969, G. Guzmán 7746 (ENCB); municipio de Zimapan, Minas Viejas, septiembre, 1981, S. Barragán 192 (ENCB).

Comentarios taxonómicos. Esta especie crece solitaria en árboles vivos o madera muerta de encino en bosque de Quercus y Quercus-Pinus causando pudrición blanca. Se distingue en el campo por su basidioma grueso y sésil de color amarillo pálido y por presentar tubos largos. Microscópicamente, se caracteriza por tener hifas generativas con abundantes fíbulas y muy ramificadas, las del contexto son de un mayor diámetro y de paredes más gruesas que las de la trama, así como esporas elipsoides. Spongipellis unicolor es afín a $S$. pachyodon, $S$. delectans y $S$. spumeus, pero se separa de la primera por presentar himenóforo hidnoide y esporas más pequeñas (de 5-6.5 $\mu \mathrm{m}$ de diámetro) y de las otras dos porque tienen el himenóforo con poros más pequeños de 1 a 3 por mm. Se conoce solamente de Norteamérica y es común en Arizona y Nuevo México.

\section{Sistotremataceae}

Sistotrema confluens Pers. : Fr. Syst. Mycol. 1: 426, 1821. Figs. 34-36

Basidioma anual, lateralmente estipitado, flabeliforme a espatulado, infundibuliforme, carnoso cuando fresco, quebradizo al secar. Píleo de 7-18 x 12-30 x 2-15 mm, de color blanquecino (4A2) a amarillento (4A3), glabro a finamente tomentoso, con finas grietas radiales, ligeramente zonado. Margen estéril, agudo, incurvado hacia adentro, de blanquecino a amarillo pálido (4A2), en algunas partes hasta de $2 \mathrm{~mm}$ de ancho. Himenóforo con poros de 1-4 por milímetro, de color amarillo pálido (4A2), angulares a irregulares con el borde dentado a lacerado. Tubos concoloros con el himenóforo, hasta de $3 \mathrm{~mm}$ de profundidad. Estípite cilíndrico, poco ensanchado hacia la base, de 6-10 x 2-4 mm, concoloro al píleo, finamente tomentoso, glabro, lateral. Contexto simple, hasta de $2 \mathrm{~mm}$ de grosor, blanquecino a crema (4A2), carnoso.

Sistema hifal monomítico, hifas generativas de 2.4-
$3.2 \mu \mathrm{m}$ de diámetro, con fíbulas y sin fíbulas, ramificadas, hialinas a amarillentas, de pared delgada, inamiloides. Cistidios ausentes. Basidios de 18.2-24.8 x 5.6-7.2 $\mu$, clavados a cilíndricos, de pared delgada, hexaspóricos, con esterigmas hasta de $2.4 \mu \mathrm{m}$ de longitud, hialinos, inamiloides. Basidiolos de 13-15 x 4.8-6.4 $\mu \mathrm{m}$, clavados, pared delgada, hialinos e inamiloides. Basidiosporas de 4.0-5.6 x 2.4-3.2 $\mu \mathrm{m}$, cilíndricas, cortas a oblongas, lisas, de pared delgada, hialinas e inamiloides.

Material estudiado. DISTRITO FEDERAL: Delegación Cuajimalpa, camino al Desierto de los Leones, La Venta, octubre, 1974, M. A. Barrios-Rodríguez 70 (ENCB). ESTADO DE MÉXICO: municipio de Amanalco de Becerra, Km 52 de la carretera Toluca-Valle de Bravo, La Hacienda, septiembre 2, 1984, Cruz-Arteaga 205 (ENCB); municipio de Ocoyoacac, Parque Nacional Lagunas de Zempoala, septiembre 13, 1959, M. Ruiz-Oronoz y T. Herrera 3709 (MEXU, ENCB); Salazar, septiembre 17, 1961, S. Ochoa 148 (ENCB); municipio de San Miguel Zinacantepec, carretera a Sultepec a $5 \mathrm{~km}$ del entronque con la de Temascaltepec, octubre 23, 1976, O. Pantoja-Ayala 59 (ENCB); municipio de Santa Ana Jilotzingo, Km 52 carretera Naucalpan-Santa Ana Jilotzingo, septiembre 16, 1984, C. Castro 117 (ENCB); municipio de Sultepec, Km 24.5 carretera Toluca-Sultepec, octubre 2, 1988, A. González-Velázquez 1003 (ENCB); municipio de Tejupilco de Hidalgo, Km 11 del camino de terrecería a cañadas de Nanchititla, septiembre 23, 1990, R. Valenzuela 7367 (ENCB), R. Valenzuela 5093 (ENCB); municipio de Temascaltepec, región del Parque Nacional Nevado de Toluca, alrededores de San Francisco Oxtotilpan, agosto 21, 1983, L. Colón 143 (ENCB), El Mapa, septiembre 3, 1972, M. S. J. León s. n. (ENCB); Km 7 de la carretera Toluca-Temascaltepec, octubre 23, 1983, R. E. Santillán 544 (ENCB); Km 54 carretera Toluca-Temascaltepec, septiembre 24, 1988, E. Hilario y L. Pérez-Ramírez 935 (FCME 14498); municipio de Valle de Bravo, al SE de Valle de Bravo, cercanías de Peña Blanca, septiembre 26, 1967, G. Guzmán 6200 (ENCB). GUERRERO: $15 \mathrm{~km}$ al SO de Mazatlán, La Iglesia, octubre, 1974, Alarcón-Guevara 192 (ENCB). DURANGO: municipio de Suchil, Reserva de la Biosfera de la Michilía, entre el Potrero Mesa Larga y arroyo de la presa Los Altares, septiembre 4, 1983, R. E. Santillán 393 (ENCB), R. Valenzuela 2465 (ENCB); Potrero Las Alazanas, Arroyo Temascal, septiembre 3, 1983, R. Valenzuela 2382 (ENCB). HIDALGO: municipio de Tianguistengo, $8 \mathrm{~km}$ al E de la desviación de Tianguistengo, septiembre 16, 1978, F. Lorea s.n. (ENCB); municipio de Mineral del Chico, Parque Nacional El Chico, Las Ventanas, septiembre 22, 1979, Guzmán 17873 (ENCB). MICHOACÁN: municipio de Cd. Hidalgo, Parque Nacional Cerro Garnica, octubre 6, 1983, F. Padilla-Hurtado11320 (FMCE). MORELOS: municipio de Huitzilac, S de Tres Marías carretera federal MéxicoCuernavaca, Atlixtac, septiembre 9, 1973, G. Guzmán 11346 (ENCB); Parque Nacional Lagunas de Zempoala, septiembre, 


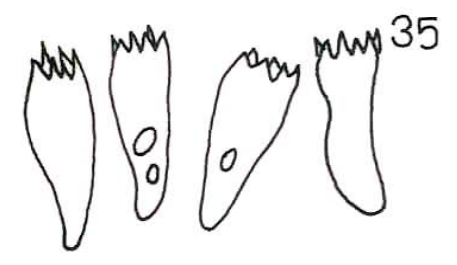

$\vartheta$

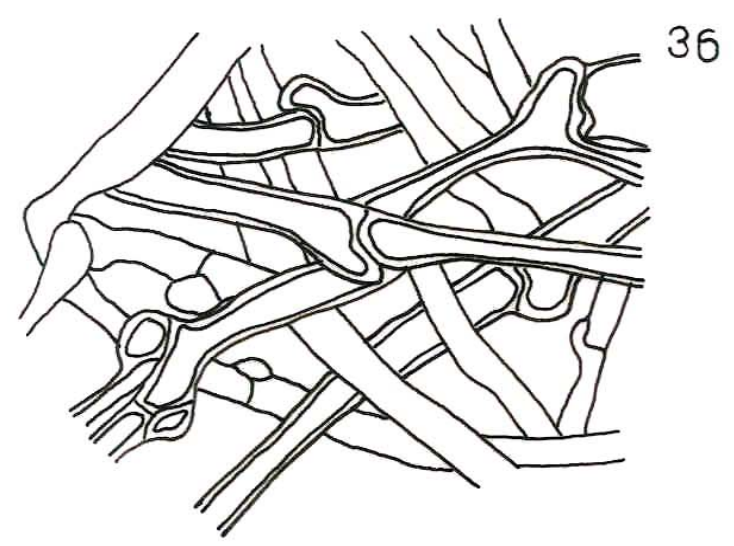

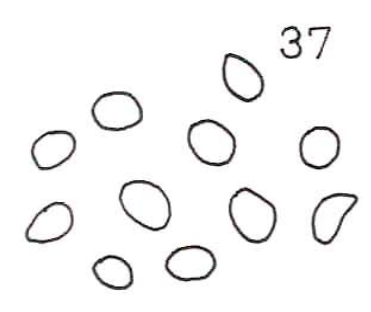

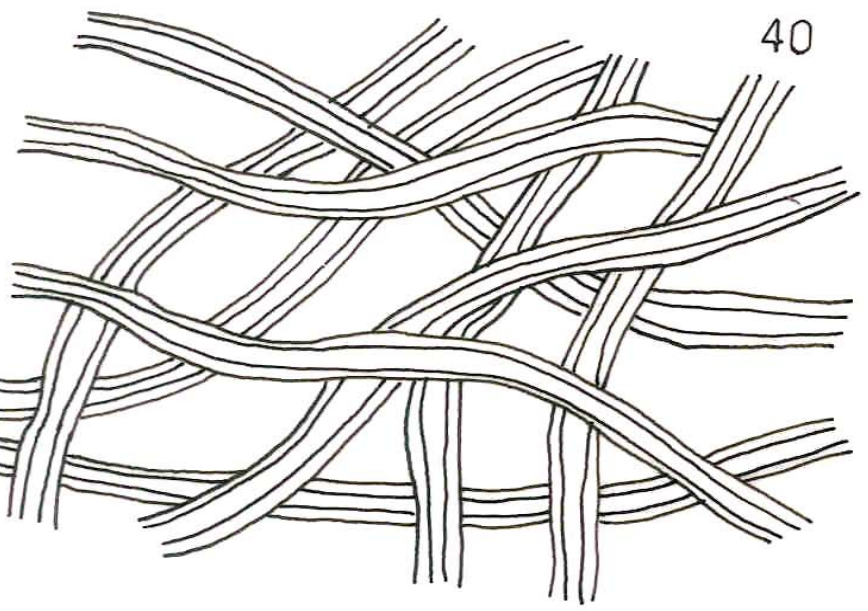

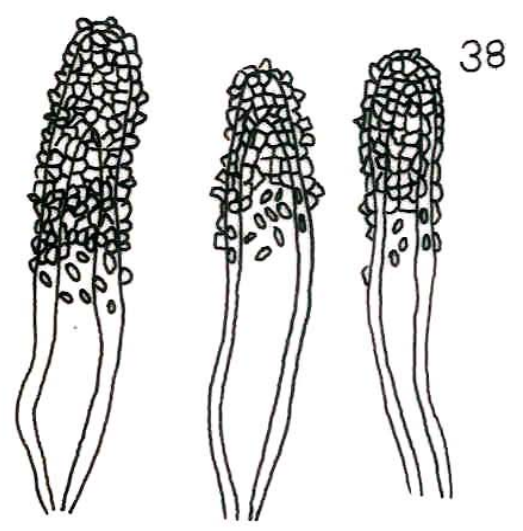

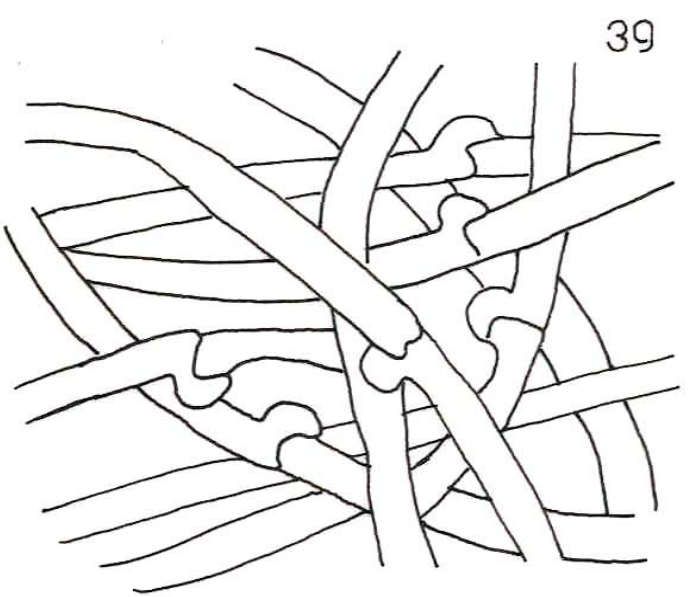

Figuras 34-40. Sistotrema confluens Persoon: Fries (34-36); 34, basidiosporas; 35, basidios; 36, sistema hifal. Junghuhnia semisupiniforme (Murrill) Ryvarden (37-40); 37, basidiosporas; 38, cistidios. Sistema hifal: 39, hifas generativas; 40, hifas esqueléticas (escala $=8 \mu \mathrm{m}$ ). 
1974, B. E. Rodríguez 36 (ENCB); municipio de Tepoztlán, curva La Pera, lado oriente, septiembre 21, 1969, M. Aguirre- Jones 80 (ENCB); septiembre 12, 1969, J. Gimate 151-B (ENCB). OAXACA: municipio de Ixtlán de Juárez, El Punto, agosto 29, 1996, H. León-Avendaño 191 (ITAO). TLAXCALA: municipio de Huamantla, Parque Nacional La Malintzi, Altamira de Guadalupe, agosto 23, 1980, I. González-Fuentes 714 (ENCB); municipio de Ixtenco, Fractura Central, ladera E volcán La Malintzi, septiembre 16, 1988, A. Montoya-Esquivel 251 (TLAX, ENCB), noviembre 4, 1988, A. Estrada-Torres 2412 (TLAX, ENCB); Km 10.5 de la autopista San Martín Texmelucan-Tlaxcala, Ixtacuixtla, septiembre 21, 1984, E. Altamirano 225 (TLAX, ENCB). VERACRUZ: municipio de Chiconguiaco, $2 \mathrm{~km}$ al N de Chiconguiaco, septiembre 1, 1988, R. Valenzuela 6234 (ENCB), R. E. Santillán 393 (ENCB).

Comentarios taxonómicos. Crece gregario a disperso, en suelo, mantillo o madera de Quercus, Pinus y Abies en bosque Quercus-Pinus, Pinus-Quercus y de Abies-Pinus ocasionando una pudrición blanca. En el género, solo $S$. confluens y $S$. muscicola presentan himenóforo poroide, ya que las otras especies tienen himenóforo liso, pero la segunda especie presenta el basidioma resupinado, carácter que lo diferencia de la primera. Esta especie tiene amplia distribución en Norteamérica y Europa (Gilbertson y Ryvarden, 1987; Ryvarden y Gilbertson, 1993) y en México se registra ahora del Distrito Federal, Durango, Guerrero, Hidalgo, Estado de México, Michoacán, Morelos, Tlaxcala y Veracruz.

\section{Stecherinaceae}

Junghuhnia semisupiniforme (Murrill) Ryvarden. Mycotaxon 23:5, 1985. Figs. 37-40.

Basidioma anual de 17 x 14 x 2 mm, efuso-reflejado, correoso. Píleo de color amarillo pálido (4A3) a amarillo brillante (4A4), de pubescente a glabro, con líneas radiales. Margen redondeado, estéril, de color amarillo pálido (4A3). Himenóforo con poros de color anaranjado pálido (5A3) a anaranjado brillante (5A4), de 5-7 por $\mathrm{mm}$, angulares, con el borde de lacerado a fimbriado. Tubos de hasta $1 \mathrm{~mm}$ de grosor, de color amarillo pálido (4A3). Contexto de color blanquecino amarillento (4A2) a amarillo pálido (4A3), de hasta $1 \mathrm{~mm}$ de grosor, correoso, simple.

Sistema hifal dimítico, con hifas generativas de $2-5 \mu \mathrm{m}$ de diámetro, fíbuladas, hialinas, inamiloides, de paredes delgadas, de simples a poco ramificadas. Hifas esqueléticas de 3-6.4 $\mu \mathrm{m}$ de diámetro, dominando en el basidioma, de hialinas a amarillentas, no ramificadas en el contexto, ligeramente ramificadas en la trama. Cistidios de 50-120 x 6.4-12 $\mu \mathrm{m}$, clavados a cilíndricos, incrustados, abundantes en la trama originándose de las hifas esqueléticas, algunos se proyectan en el himenio. Basidios no observados. Basidiosporas de 4.0-5.0 x 3.2-4.0 $\mu \mathrm{m}$, ampliamente elipsoides a subglobosas, lisas, de paredes delgadas, hialinas, inamiloides.
Material estudiado. QUERÉTARO: municipio de Landa de Matamoros, $10 \mathrm{Km}$ al sur de Agua Zarca, sobre la brecha a Pisaflores, mayo 16 1987, R. Fernández 3841 (ENCB). VERACRUZ: municipio de Papantla, El Palmar, enero 25, 1941, Grant T. J. 2196 (BPI); municipio de Xalapa, Xalapa, diciembre 12, 1909, W. A. Murrill y E. L. Murrill 353 (Holotipo, NY).

Comentarios taxonómicos. Esta especie crece sobre madera muerta de angiospermas en bosques de encino, mesófilo de montaña y tropical subperenifolio y ocasiona pudrición blanca. Además, se caracteriza por presentar basidiomas pileados, el tamaño y forma de las esporas que la hacen diferente de las demás especies del género Junghuhnia. Una especie afín es J. pseudozillingiana pero presenta esporas más alargadas y poros más grandes, de 2-3 por mm. La especie fue descrita para el estado de Veracruz por Murrill (1912) de un bosque mesófilo de montaña. Esta especie sólo se conocía de la localidad tipo en el Veracruz y posteriormente fue registrada en Italia por Ginns y Bernicchia (1984), pero la sitúan en el género Flaviporus, posteriormente Ryvarden y Gilbertson (1993) la mencionan de Europa basados en el registro de dichos autores, pero como parte del género Junghuhnia.

\section{Discusión}

La mayoría de las especies estudiadas en este trabajo, fueron registradas para México en listados, sin presentar una descripción detallada de los ejemplares, como es el caso de Bjerkandera fumosa, Ceriporia excelsa, C. xylostromatoides, Fistulina hepatica, Oxyporus populinus, Perenniporia tenuis, Skeletocutis ochroalba, Spongipellis unicolor y Sistotrema confluens. En el presente estudio, además de hacer las redescripciones basadas en ejemplares mexicanos, se amplía la distribución de las siguientes especies: Bjerkandera fumosa se registra por primera vez para el Estado de México, Hidalgo y Veracruz; se extiende la distribución de Ceriporia xylostromatoides a Morelos, Sinaloa y Sonora, de Fistulina hepatica al Estado de México y Veracruz; de Perenniporia tenuis al Estado de México, de Skeletocutis ochroalba al Estado de México e Hidalgo, de Spongipellis unicolor a Hidalgo y finalmente Sistotrema confluens se registra por primera vez para el Distrito Federal, Durango, Estado de México, Guerrero, Hidalgo, Michoacán, Morelos, Tlaxcala y Veracruz.

Por último, Oligoporus hibernicus se registra por primera vez para la micobiota de México.

\section{Agradecimientos}

Los autores agradecen a los curadores de los Herbarios ARIZ, BPI, LUND, NY en Estados Unidos de América 
y de los Herbarios FCME, ITAO, MEXU y UJED en México por las facilidades otorgadas para la revisión de los ejemplares que se citan en este trabajo. Se hace patente nuestro agradecimiento a PAPIIT IN209605-3 (UNAM) por el apoyo financiero otorgado para la realización del presente trabajo.

\section{Literatura citada}

Bandala, V. M., G. Guzmán y L. Montoya. 1993. Los hongos del grupo de los poliporáceos conocidos en México. Reporte Científico, Núm. Esp. 13: 1-55.

Brusis, O. A. 1972. A new species of Fistulina from Mexico. Mycologia 64: 1248-1252 .

Castillo, J. y G. Guzmán. 1970. Estudios sobre los poliporáceos de Nuevo León, II.. Boletín de la Sociedad Botánica de México 31: 1-47.

Castillo, J., G. Guzmán y G. Sepúlveda. 1969. Estudios sobre los poliporáceos de Nuevo León. Ciencia 27: 9-18.

Cifuentes-Blanco, J., M. Villegas-Ríos, R. García-Sandoval, G. Vidal-Gaona, S. Sierra-Galván, R. Valenzuela-Garza, L. Pérez-Ramírez y E. Morales-Torres. 2004. Distribución de macromicetos: una aproximación al análisis de áreas de endemismo. In Biodiversidad de la Sierra Madre Oriental, I. Luna, J. J. Morrone y D. Espinosa (eds.), CONABIOUNAM, México. p. 355-374.

Díaz-Moreno, R., J. G. Marmolejo y R. Valenzuela. 2005. Flora micológica de bosques de pino y pino-encino en Durango, México. Ciencia. Universidad Autónoma de Nuevo León. 8: 362-369.

Farr, D., G. F. Bills, G. P. Chamuris y A. Y. Rossman. 1989. Fungi on plants and plant products in the United States. APS, St. Paul, Minnesota. 1252 p.

Gilbertson, R. L. y J. L. Lowe. 1962. Notes on western polypores II. New distribution records. Papers of the Michigan Academy of Sciences, Arts and Letters 47: 165179.

Gilbertson, R. L. y L. Ryvarden. 1986. North American polypores, vol. 1. Abortiporus-Lindteria,. Fungiflora, Oslo. $443 \mathrm{p}$.

Gilbertson, R. L. y L. Ryvarden. 1987. North American polypores, vol. 2. Megasporoporia- Wrightoporia. Fungiflora, Oslo. p. 434-885.

Ginns, J. H. 1980. The genus Flaviporus Murrill (Polyporaceae). Canadian Journal of Botay 58: 15781590.

Ginns, J.H.y A. Bernichia. 1984. Flaviporus semisupiniformis (Polyporaceae) in Italy. Mycologia Helvetica 1: 185188.

Guzmán, G. y T. Herrera. 1971. Especies de macromicetos citadas de México, II. Fistulinaceae, Meruliaceae y Polyporaceae. Boletín de la Sociedad Mexicana de Micología 5: 57-77.

Holmgren, P. K., N. H. Holmgren y L. C. Barnett. 1990.
Index Herbariorum. Part I: The herbaria of the world. New York Botanical Garden, New York. 693 p.

Kornerup, A. y J. H. Wanscher. 1978. Methuen handbook of colour, $3^{\text {a }}$ Ed. Eyre Methuen,. London. 252 p.

Laferriere, J. E. y R. L. Gilbertson. 1992. Fungi of Nabogame, Chihuahua, México. Mycotaxon 44: 73-87.

Largent, L., D. Johnson y R. Walting. 1977. How to identify mushrooms to genus. III. Microscopic features. Mad River, Eureka, California. 148 p.

Lowe, J. L. 1963. A synopsis of Poria and similar fungi from the tropical regions of the world. Mycologia 55: 453-486.

Lowe, J. L. 1966. Polyporaceae of North America. The genus Poria Technical Publications 90, State University Collection. Forestry, Syracuse University, Nueva York.

Lowe, J. L. 1975. Polyporaceae of North America. The genus Tyromyces. Mycotaxon 2: 1-82.

Murrill, W. A. 1912. The Polyporaceae of Mexico. Bulletin New York Botanical Garden 8: 137-153.

Murrill, W. A. 1920. Light-colored resupinate polypores. I. Mycologia 12: 77-92.

Pérez-Silva E., M. Esqueda-Valle y M. Amaya-López. 1993. Nuevos registros de Aphyllophorales de Sonora, México. Ecologica 3:23-28.

Raymundo, T. y R. Valenzuela. 2003. Los poliporáceos de México VI. Los hongos poliporoides del estado de Oaxaca. Polibotánica 16: 79-112.

Reyes-Garza, C. 1969. Especies del género Fomes (Basidiomycetes, Polyporaceae) en el estado de Nuevo León, México. Tesis, Facultad de Ciencias Biológicas, Universidad de Nuevo León, Monterrey, México. 44 p.

Riviero-Teixeira, A. 1993. Chave para identiçao dos géneros de Polyporaceae com base na morfologìa do basidiocarpo. Boletim do Instituto de Botânica 8:1-55.

Rossman, A. 1994. A strategy for all-taxa inventory of fungal biodiversity. In Biodiversity and terrestral ecosystems, Monograph Series 14, C. I. Peng y C. H. Chou (eds.). Institute of Botany, Academic Sinica, p. 169-194.

Ryvarden, L. 1976. The Polyporaceae of North Europe, vol 1. Albatrellus- Incrustoporia. Fungiflora, Oslo. 214 p.

Ryvarden, L. 1985. Type studies in Polyporaceae. 17. Species described by W. A. Murrill. Mycotaxon 223: 169-198.

Ryvarden, L. y I. Johansen. 1980. A preliminary polypore flora of East Africa, Fungiflora, Oslo, 636 p.

Ryvarden, L. y G. Guzmán. 1993. New and interesting Polypores from Mexico. Mycotaxon 47: 1-23.

Ryvarden, L. y G. Guzmán. 2001. Studies in neotropical polypores 12. New and noteworthy polypores from México. Mycotaxon 78: 245-256

Ryvarden, L. y R. L. Gilbertson. 1993. European polypores, vol. I, Abortiporus - Lindtneria. Fungiflora, Oslo. 387 p.

Valenzuela, R., C. P. de la Huerta y R. Fernández. 2002. Los poliporáceos de México. V. Algunas especies del norte del estado de Querétaro. Polibotánica 14: 85-113.

Valenzuela, R., R. Nava y J. Cifuentes. 1994. El género 
Albatrellus en México. I. Revista Mexicana de Micología 10: 113-52.

Valenzuela, R., R. Nava y J. Cifuentes. 1996. La familia Hymenochaetaceae en México I. El género Hydnochaete Bres. Polibotánica 1: 7-15.

Valenzuela, R., T. Raymundo y J. Cifuentes. 2005. La familia Hymenochaetaceae en México II. Especies poco conocidas del género Phellinus. Revista Mexicana de Micología 20: 13 -19.

Valenzuela, R., T. Raymundo y R. Fernández-Nava, 2004. Los poliporáceos de México VII. Primer registro de
Perenniporia Gilbertson \& Blackwell y Trechispora regularis (Murrill) Liberta. Polibotánica 17: 103106.

Welden, A. L. y P. A. Lemke. 1961. Notas sobre algunos hongos mexicanos. Boletín de la Sociedad Botánica de México. 26: 1-24.

Zarco, J. 1986. Estudio de la distribución ecológica de los hongos (principalmente macromicetos) en el Valle de México, basado en especímenes depositados en el Herbario ENCB. Revista Mexicana de Micología 2: 41-72. 